\title{
Intracervical PGE2 gel for induction of labour in patients with prelabour rupture of membranes with unfavorable cervix after 34 weeks period of gestation
}

\author{
Sheela Jayaprakash*, Lakshmidevi Muralidhar, Shreedhar Venkatesh
}

\begin{abstract}
Department of Obstetrics and Gynaecology, Vydehi institute of medical sciences and research centre, EPIP area, Nallurahalli, Bangalore, Karnataka, India
\end{abstract}

Received: 17 February 2016

Revised: 16 March 2016

Accepted: 18 March 2016

\author{
*Correspondence: \\ Dr. Sheela Jayaprakash, \\ E-mail: drsheelajp@gmail.com
}

Copyright: (C) the author(s), publisher and licensee Medip Academy. This is an open-access article distributed under the terms of the Creative Commons Attribution Non-Commercial License, which permits unrestricted non-commercial use, distribution, and reproduction in any medium, provided the original work is properly cited.

\begin{abstract}
Background: Premature rupture of membranes (PROM) occurs in 5-10\% of all pregnancies. Approximately $60 \%$ of cases of PROM occur in term patients. Intra-vaginal or intra-cervical PGE2 has been found to be efficacious in inducing labour at term with the majority of patients delivered with or without the aid of oxytocin, most within 24 hours. But the use of PGE2 gel in patients with PROM and unfavorable cervix to induce labour is not widely accepted possibly for fear of introduction of infection and for draining away the gel with liquor. The objective of this study was to evaluate the efficacy of prostaglandin E2 gel (Dinoprostone $0.5 \mathrm{mg}$ ) for induction of labour in patients with PROM at term and 34-37 weeks of gestation with an unfavorable cervix.

Methods: Study was performed at Vydehi Institute of Medical Sciences and Research Centre from February 2013 to June 2015. Eligible patients included those at term and 34 to 37 weeks of gestation with spontaneous rupture of membranes who presented before onset of labour. All patients had singleton pregnancy with vertex presentation. All patients received a single intra-cervical application of $0.5 \mathrm{mg}$ PGE2 gel. If labour was not established at 6 hours, repeat cervical assessment was done and those with unfavorable cervix received 2nd dose of intra-cervical application of PGE2 gel. After an additional 6 hours, patients with low Bishop's scores were tried with oxytocin titration infusion.

Results: Of the 80 patients 68 patients $(85 \%)$ began labour after single application, 12 patients $(15 \%)$ required $2^{\text {nd }}$ dose of PGE2. 22 patients $(25 \%)$ required augmentation with oxytocin. 6 patients landed up with cesarean section. Mean interval between prostaglandin application and delivery was 11.5 hours. No significant maternal and neonatal infectious morbidity was seen in the study.

Conclusions: Intra-cervical PGE2 gel is safe and effective for inducing labour in patients with PROM with unfavorable cervix. In our study we had high rate of vaginal delivery with no infectious morbidity.
\end{abstract}

Keywords: PROM, PGE2 gel, Labour

\section{INTRODUCTION}

Pre labour rupture of membranes (PROM) occurs in 5$10 \%$ of all pregnancies. Approximately $60 \%$ of cases of PROM occur in term patients. The etiology and pathophysiology of PROM is obscure and hence opinion regarding management of this disorder varies widely. ${ }^{1}$ pre labour rupture of membranes is associated with maternal and neonatal infection, cord prolapse and fetal compromise which may result in operative delivery or low APGAR score at five minute. ${ }^{2}$ Pre labour rupture of membranes is also associated with chorioamnionitis in 6$10 \%$ of women at term and up to $40 \%$ in women with membranes ruptured for more than 24 hours. Therefore 
obstetricians find it necessary to induce labour in these patients to avoid complications to both mother and child. ${ }^{3}$

Induction of labour is the only strategy besides expectant management for PROM after 34 weeks of period of gestation that reduces the infectious morbidity for both mother and infant. Various agents have been introduced to stimulate uterine contractions and for cervical ripening but only few have been scientifically evaluated. Intravenous Oxytocin and different preparations of prostaglandins have been used for inducing labour but the effectiveness of all these agents varies. ${ }^{4,5}$ There is considerable disparity that exists regarding the most appropriate course of management which contributes to the confusion.

Women managed expectantly will go into spontaneous labour and delivery within 24, 48 and 72 hours of PROM in 70,85 and 95 per cent of cases, respectively. ${ }^{6}$ However the available evidence suggests that immediate induction of labour presents the most favourable outcome profile for pregnancies complicated by PROM at term.

Expectant management policy may be justified initially but postnatal complications are observed in $17 \%$ of patients managed expectantly. Neonatal risks of expectant management include infections (2.8\%), admission to intensive care unit $(8 \%)$, placental abruption, fetal distress (2\%), fetal restriction deformities, pulmonary hypoplasia and neonatal death $(1 \%) .^{7}$

Intra-vaginal or intra-cervical PGE2 gel has been found to be efficacious in inducing labour at term with the majority of patients delivered with or without the aid of oxytocin, most within 24 hours. The success depends on the dose of prostaglandin, site of administration, condition of the cervix at the time of induction and parity. The rate of caesarean section is found to be low in these patients. Side effects have been few and uterine hyper tonicity encountered infrequently.

The use of PGE2 preparations for induction of labour in patient with unfavourable cervix is widely accepted and practiced. But the use of PGE2 gel in patients with PROM and unfavourable cervix to induce labour is not widely accepted possibly for fear of introduction of infection and also draining away gel with liquor. So we conducted a retrospective study at Vydehi institute of medical sciences and research centre, EPIP area, Nallurahalli, Bangalore, Karnataka, India.

The objective of this study was to evaluate the efficacy of prostaglandin E2 gel (Dinoprostone $0.5 \mathrm{mg}$ ) for induction of labour in patients with PROM at term and 34-37 weeks of gestation with an unfavorable cervix. And To know about maternal and neonatal outcome in patients with PROM induced with PGE2 gel.

\section{METHODS}

Study was performed at Vydehi institute of medical sciences and research centre, EPIP area, Nallurahalli, Bangalore, Karnataka, India. From February 2013 to June 2015. Women with a live singleton fetus after 34 weeks of gestation with cephalic presentation.

\section{Inclusion criteria}

- More than 34 weeks of gestation with spontaneous rupture of membranes who presented before onset of labour

- $\quad$ Singleton pregnancy with vertex presentation

- Reactive non-stress test (NST)

- A Bishop score of 6 or less before the onset of labor

\section{Exclusion criteria}

- Favorable cervix with Bishops score more than 6

- Singleton pregnancy with doubt of PROM

- Patients with medical and obstetric complications

- Non vertex presentation

A sterile speculum examination was performed to confirm obvious leakage of amniotic fluid. A digital examination was performed to assess the Bishop's score and to exclude occult cord prolapse. A poor Bishop's score was assessed as one with 6 and below. A cardiotocograph was done to assess the fetal well-being and to confirm the absence of contractions.

All patients received a single intra-cervical application of $0.5 \mathrm{mg}$ PGE2 gel. If labour was not established at 6 hours, repeat cervical assessment was done and those with unfavorable cervix received 2 nd dose of intra-cervical application of PGE2 gel. After 6 hours of 2nd application, patients with low Bishop's scores were labeled as failed induction cases with PG E2 gel. Labour augmented with oxytocin in those patients where cervix became favorable but not in established labour.

All patients received prophylactic antibiotics on admission (1gm ampicillin stat and $500 \mathrm{mg}$ every $6^{\text {th }}$ hourly parentally till delivery later on switched to oral therapy). Details of labour and maternal and fetal outcome data were collected. Chorioamnionitis was diagnosed if maternal temperature exceeded 38 degrees Celsius during labour without evidence of other sources of infection. Endometritis was diagnosed when maternal temperature exceeded 38 degrees Celsius on two occasions or 38.5 degrees Celsius on one occasion after the first 24 hours postpartum when uterine tenderness, foul smelling lochia was present or other sources of fever were excluded. Neonates treated according to NICU protocol.

Statistical analysis done by using percentage chart. 


\section{RESULTS}

In our study total number of PROM cases were 80 . Incidence of Prom according to our study is $6.8 \%$. Mean maternal age was 28 years. In our study $68(85 \%)$ patients with PROM were of gestational age of more than 37 weeks and $12(15 \%)$ patients were of 34-37 weeks. In our study $54(67.5 \%)$ patients were nullipara and 26 $(32.5 \%)$ patients were multipara. In our study mean duration of rupture of membranes was 10 hours. Mean cervical score at the time of admission was 3.68. Women with PROM were induced with single dose of PG E2 gel was 68 patients i.e. $85 \%$. 12 women i.e. $15 \%$ required 2nd dose of PGE2 gel. Out of 80 patients 22 women required oxytocin during the process of delivery, 16 women required for augmentation and 6 women required oxytocin for cervical priming after the failure of 2 nd dose of PGE2 gel (Table 1).

Table 1: Basic details of the patients.

\begin{tabular}{|c|c|c|}
\hline Total number of patients & 80 & \\
\hline Incidence & $6.8 \%$ & \\
\hline Mean maternal age & 28 years & \\
\hline \multicolumn{3}{|l|}{ Gestational Age } \\
\hline Term (>37 weeks) & 68 patients & $85 \%$ \\
\hline 34-37 weeks & 12 patients & $15 \%$ \\
\hline \multicolumn{3}{|l|}{ parity } \\
\hline Nulliparous & 54 patients & $67.5 \%$ \\
\hline Multiparous & 26 patients & $32.5 \%$ \\
\hline \multicolumn{3}{|l|}{$\begin{array}{l}\text { Duration of rupture of } \\
\text { membranes on admission }\end{array}$} \\
\hline 2-4 hours & 14 & \\
\hline 4-6 hours & 26 & \\
\hline $6-8$ hours & 22 & \\
\hline 8-18 hours & 18 & \\
\hline $\begin{array}{l}\text { Mean duration of rupture of } \\
\text { membranes on admission }\end{array}$ & 10 hours & \\
\hline Mean cervical score & 3 & \\
\hline $\begin{array}{l}\text { No. of patients where labour } \\
\text { was induced with single } \\
\text { application }\end{array}$ & 68 patients & $85 \%$ \\
\hline $\begin{array}{l}\text { No. of patients who required } \\
2^{\text {nd }} \text { application }\end{array}$ & 12 patients & $15 \%$ \\
\hline Use of oxytocin & 22 patients & $27.5 \%$ \\
\hline For augmentation & 16 patients & \\
\hline After 2 cerviprime & 6 patients & \\
\hline
\end{tabular}

In our study 74 patients i.e. $92 \%$ delivered vaginally, out of them 12 women required outlet forceps delivery. Only 6 patients ended up with caesarean section, indication for caesarean section were failed induction in 4 patients and fetal distress in 2 patients. Mean interval of PROM to onset of labour was 10 hours and mean length of labour was 11.5 hours. Mean duration of PROM to delivery was 21.5 hours. Maternal pyrexia was noted in 2 patients and neonatal infection was noted in 6 neonates ( 2 term and 4 preterm neonates). 22 neonates received prophylactic antibiotics, i.e. 10 term neonates and 12 preterm neonates. APGAR score was less than 7 at $1 \mathrm{~min}$ in 2 term and 8 preterm neonates. APGAR score at 5 minutes was less than 7 in 2 preterm neonates (Table 2).

Table 2: Intra-partum details.

\begin{tabular}{|c|c|c|}
\hline \multicolumn{3}{|l|}{ Mode of delivery } \\
\hline Total vaginal delivery & 74 patients & $92 \%$ \\
\hline Normal vaginal delivery & 62 patients & $77 \%$ \\
\hline Outlet forceps delivery & 12 patients & $15 \%$ \\
\hline Caesarean section & 6 & $8 \%$ \\
\hline For failed induction & 4 & \\
\hline Foetal distress & 2 & \\
\hline $\begin{array}{l}\text { Mean interval from PROM } \\
\text { to labour onset }\end{array}$ & 10 hours & \\
\hline Mean length of labour & 11.5 hours & \\
\hline $\begin{array}{l}\text { Mean interval from PROM } \\
\text { to delivery }\end{array}$ & 21.5 hours & \\
\hline \multicolumn{3}{|l|}{$\begin{array}{l}\text { Maternal and Neonatal } \\
\text { infection }\end{array}$} \\
\hline Maternal pyrexia & 2 & \\
\hline $\begin{array}{l}\text { Signs and symptoms of } \\
\text { infection in neonate }\end{array}$ & 6 & $\begin{array}{l}\text { Term-2, } \\
\text { Preterm-4 }\end{array}$ \\
\hline Prophylactic antibiotics & 22 & $\begin{array}{l}\text { Term-10, } \\
\text { Preterm-12 }\end{array}$ \\
\hline Neonatal outcome & Term & $\begin{array}{l}\text { Preterm } \\
(34-37 \\
\text { weeks })\end{array}$ \\
\hline $\begin{array}{l}\text { Neonate with APGAR <7 } \\
\text { at } 1 \text { min }\end{array}$ & 2 & 8 \\
\hline $\begin{array}{l}\text { Neonate with APGAR }<7 \\
\text { at } 5 \text { minutes }\end{array}$ & 0 & 2 \\
\hline Admission to NICU & 14 & \\
\hline Preterm & 12 & \\
\hline Term & 2 & \\
\hline
\end{tabular}

\section{DISCUSSION}

The mean interval between PGE2 gel use and delivery was 11.5 hours. This is slightly less when compared to other studies. (10.5 in Rijal H study and Gupta A study, 16.3 hours in Ray and Garite and 12 hours in Chua et al). It may be because we use gel intra-cervically where as others used mainly suppository in the posterior fornix. Number of patients who required oxytocin for augmentation was $16(27.5 \%)$. It is comparable with the other studies (37.5\%-Ray and Garite, $2.64 \%$ Meikle et al and $55 \%$ in $\mathrm{H}$ Rijal study). About $92.5 \%$ delivered vaginally, $77.5 \%$ normally and $15 \%$ by outlet forceps delivery, this is comparable to $\mathrm{H}$ Rijal study i.e. $90 \%$. $^{3,8-11}$

Caesarean delivery was required in 6 patients $(7.5 \%)$ with indications of failed induction in 4 and fetal distress in 2. It is comparable with other studies (11\% in H Rijal study, $14.3 \%$-Ray and Garite, $13.9 \%$ in Chua et al and $12 \%$ in Meikle et al). ${ }^{3,9-11}$ 
Maternal side effects were minimal. There were no instances of hyper stimulation in either group. Only one patient had pyrexia after delivering with no other symptoms of endometritis. It was self-limiting. This maybe because all received prophylactic antibiotics and duration of delivery was less. $(2.5 \%$ in Chua et al, $8.8 \%$ in Meikle et al). ${ }^{3,8-11}$

Seven neonates were admitted to neonatal intensive care unit. Among these 6 were preterm and 1 was term and only one neonate had Apgar score $<7$ at 5 minutes. All babies who were admitted to NICU received prophylactic antibiotics. One infant among the preterm babies had sepsis and was treated accordingly. All had uneventful neonatal hospital stays. $2.8 \%$ (term babies), $4.5 \%$ Ray and Garite, $1-3.4 \%$ cases in our studies, $2.79 \%$ cases in Chua et al. ${ }^{8-11}$
In a study conducted by Ezechi OC for induction of labour in PROM patients with PG E1 (misoprostol) LSCS rate was $18.6 \%$, Hyper stimulation rate was $3 \%$ Rate of fetal distress was $10.2 \%$ and birth asphyxia rate was $3 \%$ which is more in comparison to our study. ${ }^{12}$

In a study conducted by Bangal VB et al vaginal delivery rate was $88 \%$, LSCS rate was $12 \%$, fetal distress was seen in $8 \%$ of the patients and hyper bilirubinemia in $20 \%$ of the patients, the rate of normal delivery is less compared to our study and fetal distress is more compared to our study. ${ }^{13}$

In our study the interval to delivery and the incidence of maternal and neonatal infections was less with intracervical PGE2 gel followed by oxytocin augmentation if necessary (Table 3).

Table 3: Comparison with other studies.

\begin{tabular}{|c|c|c|c|c|c|c|}
\hline & $\begin{array}{l}\text { Our } \\
\text { study }\end{array}$ & $\begin{array}{l}\text { Oliver C } \\
\text { Ezechi study }\end{array}$ & $\begin{array}{l}\text { Vidyadhar B. } \\
\text { Bangal study }\end{array}$ & $\begin{array}{l}\text { Ray and } \\
\text { Garite }\end{array}$ & Chua et al & $\begin{array}{l}\text { Meikle et } \\
\text { al study }\end{array}$ \\
\hline $\begin{array}{l}\text { Mean interval between PGE2 } \\
\text { gel to delivery }\end{array}$ & $\begin{array}{l}11.5 \\
\text { hours }\end{array}$ & 10.5 & 10.5 & 16.5 hours & 12 hours & 17 hours \\
\hline Requirement of oxytocin & $27.5 \%$ & $55 \%$ & & $37.5 \%$ & - & $64 \%$ \\
\hline Delivered vaginally & $92.5 \%$ & 88.9 & $78 \%$ & & & \\
\hline Caesarean delivery & $7.5 \%$ & 11.1 & $22 \%$ & $14.5 \%$ & $13.9 \%$ & $12 \%$ \\
\hline Maternal morbidity & $2.5 \%$ & $11 \%$ & & - & $2.5 \%$ & $8.8 \%$ \\
\hline Neonatal morbidity & $2.8 \%$ & $2.7 \%$ & $2.0 \%$ & $4.5 \%$ & $2.6 \%$ & $24 \%$ \\
\hline
\end{tabular}

\section{CONCLUSIONS}

There is no consensus as to what is the time interval between rupture of membranes and onset of contractions should be used. In PROM immediate induction versus a policy of expectant management is one issue unresolved issue by clinical research to date. Active management of term PROM with induction is associated with reduced maternal infective morbidity without increasing caesarean or operative vaginal birth.

Prostaglandin E2 is commonly used for ripening the cervix and for inducing labour in patients with intact membranes. In women with ruptured membranes use of PGE2 gel preparations has caused concern because the placement of a "foreign body" may increase the rate of chorioamnionitis, endometritis and neonatal sepsis. From this study, the use of intra-cervical PGE2 gel with ruptured membranes is accompanied by a high vaginal delivery $(92.5 \%)$ and a low rate of complications. The use of PGE2 significantly reduced the need for oxytocin and was highly successful independently in inducing labour, with nearly two-third of the patients not requiring oxytocin and even more in parous patients.
Funding: No funding sources Conflict of interest: None declared

Ethical approval: The study was approved by the Institutional Ethics Committee

\section{REFERENCES}

1. Amjad N, Rasheed F, Imran T. Comparison of the response of oxytocin versus prostaglandin E2 vaginal pessary for labour induction in pre labour rupture of membranes. Annals. 2009;15:80-4.

2. Royal college of obstetricians and gynecologists (rcog). induction of labour, evidence-based clinical guideline number 9. rcog clinical effectiveness support unit. London: RCOG press; 2001.

3. Hannah ME, Ohlsson A, Farine D, Hewson SA, Hodnett ED, Myhr TL, et al. Induction of labour compared with expectant management for pre labour rupture of membranes at term PROM study group. $\mathrm{N}$ Engl J Med.1996;334:1005-10.

4. Conway D, Prendiville P, Morris A, Speller D, Stirrat G. Management of spontaneous rupture of the membranes in the absence of labour in primigravida women at term. Am J Obstet Gynecol. 1984;150:947-51. 
5. The Royal Australian and New Zealand college of obstetricians and gynaecologists. (C-obs-36). Term prelabour rupture of membranes. http://www.rancog.edu.au/component/docman/doc download /969-c-obs-36-term-pre-labour-ruptureofmembranes-html.

6. Hannah ME. Induction of labor compared with expectant management for pre labour rupture of the membranes at term. New England $J$ Med. 1996;334:1005-10.

7. Jazayeri A, Galan H. Premature rupture of membranes. 2006 Available from: URL: http://www.emedicine.com/med/topic3246.htm.

8. Gupta A, Kumari S. Prostaglandin E1 tablet versus prostaglandin E2 gel for induction of labor in prelabor rupture of membranes at term International Journal of Enhanced Research in Medicines \& Dental Care. 2015;2(6):1-7.

9. Chau S, Arulkumaran S, Yap C, Selamat N, Ratnam SS. PROM with unfavourable cervix, obstet gynaecol. 1995;86:550-4.
10. Ray DA, Garite TJ. PGE2 for induction of labour in patients with PROM at term. AmJ obstet gynaecol. 1992;166:836-43.

11. Meikle SF, Bissell ME, Freedman WL. A retrospective review of the efficacy and safety of prostaglandin E2 with premature rupture of the membranes at term. Obstet Gynaecol. 1992;80:4670 .

12. Ezechi OC, Lot OM, Ezeobi PM, Okogbo FO, Gbajabiamila T, Nwokoro CA. Safety and efficacy of misoprostol in induction of labour in pre labour rupture of fetal membrane in Nigerian women: a multicenter study Iranian Journal of Reproductive Medicine. 2008;6(2):83-7.

13. Bangal VB, Giri PA, Shah BG. A comparative study of outcome of labour induction with vaginal misoprostol versus intravenous oxytocin in premature rupture of membranes beyond 36 weeks of gestation Int J Pharm Biomed Res. 2011;2(4):233-6.

Cite this article as: Jayaprakash S, Muralidhar L, Venkatesh S. Intracervical PGE2 gel for induction of labour in patients with prelabour rupture of membranes with unfavorable cervix after 34 weeks period of gestation. Int $\mathbf{J}$ Reprod Contracept Obstet Gynecol 2016;5:1418-22. 